\title{
Approaches, limitations and challenges in development of biomarker-based strategy for impact assessment of neuroactive compounds in the aquatic environment
}

\author{
Sonja Kaisarevic ${ }^{*} \mathbb{0}$, Irina Vulin, Dina Tenji, Tanja Tomic and Ivana Teodorovic
}

\section{Background and objective}

Neuroactive compounds (NCs) represent a large group of chemicals that affect the activity of the nervous system of target organisms through various primary modes of action (MoA). This group of compounds includes neuroactive pharmaceuticals (antidepressants, antipsychotics, anxiolytics, anticonvulsants, opioids, and morphine derivatives), stimulants, illicit drugs, and pesticides with neuroactive action (organophosphate, carbamate, organochlorine, pyrethroid and neonicotinoid insecticides). The global use of NCs is increasing with growing of urban population and adoption of urban lifestyle $[1,2]$. Antidepressants, anxiolytics, and antipsychotics are among the most frequently prescribed drugs [2,3], caffeine is one of the most widely consumed stimulants in the world $[4,5]$, while pesticides are still extensively used in agriculture worldwide [6].

Along with neuroactive pesticides, contamination of the aquatic ecosystems by neuroactive pharmaceuticals and illicit drugs lately came into the scientific spotlight, and the increasing trend of their consumption worldwide implies to even growing environmental concentrations in the years to come. Clearly, NCs represent a newly recognized hazard in the aquatic environment, with possible adverse effects on aquatic ecosystems and implications to human population. However, the questions whether and

\footnotetext{
*Correspondence: sonja.kaisarevic@dbe.uns.ac.rs Laboratory for Ecophysiology and Ecotoxicology-LECOTOX, Department of Biology and Ecology, University of Novi Sad, Faculty of Sciences, Trg Dositeja Obradovica 3, 21000 Novi Sad, Serbia
}

to what extent NCs present a risk for aquatic ecosystems still remain largely open, due to, as the paper will show, limitations of current approaches in environmental risk and ecological impact assessment of chemicals. We will explore the potential way forward by using the Adverse Outcome Pathway (AOP) concept for the development of biomarker-based strategy for identification and hopefully, prediction of ecological impacts of NCs in aquatic ecosystems.

\section{Neuroactive compounds (NCs) (-an emerging hazard) in aquatic environment}

The intensive use of NCs results in their constant release in the environment, either in a form of parent compounds or as their active metabolites, with surface waters being most affected through municipal wastewater effluents or agricultural surface runoff and leaching. Wastewater treatment plants are not able to eliminate NCs completely, so they remain in effluents in concentrations ranging from ng/L up to $\mu \mathrm{g} / \mathrm{L}$ (reviewed by [2]).

Thanks to advanced analytical non-target screening (NTS) with state-of-the-art gas- and liquid-chromatography high-resolution mass spectrometry (GC-HRMS and LC-HRMS) and rapidly developing automated data analysis workflows, a comprehensive analysis of chemical pollution of waters is increasingly available [7]. However, apart from several neurotoxic insecticides, neuroactive pharmaceuticals and other compounds with potential neurotoxic properties are not included into mandatory official surface water and wastewater treatment plant effluent monitoring programs, so the official data on 
NCs in aquatic resources are very scarce. The available open data are patchy and derive mainly from specific projects and targeted sites. By compiling the results of occurrence of organic contaminants in seven independent monitoring studies of European freshwaters, Busch et al. [8] showed that majority of detected compounds are from the group of pesticides (42\%), followed by pharmaceuticals and illicit drugs (34\%) and industrial chemicals (17\%). Moreover, among all those contaminants, the largest group with an assignable MoA are compounds that are known to interact with the nervous system (18\%) through more than ten different molecular mechanisms or targets. Zhou et al. [9] analyzed the data collected from peer-reviewed publications and government reports on levels of pharmaceuticals in surface waters in 34 European countries, and revealed that $26 \%$ of compounds are from the groups characterized by neuroactive MoA. In the receiving waters, pharmaceuticals are detected in concentrations ranging from $\mathrm{ng} / \mathrm{L}$ to $\mu \mathrm{g} / \mathrm{L}$ [10] depending on compound and distance of sampling site from the wastewater treatment plant discharge points, while their chemical properties and detection in fish tissues suggest that some of these compounds have the potential to bioaccumulate (reviewed by [11]). As presented by Zhou et al. [9], mean concentrations of most frequently analyzed neuroactive pharmaceuticals in European surface waters were: tramadol $1127 \mathrm{ng} / \mathrm{L}$, caffeine $885 \mathrm{ng} / \mathrm{L}$, carbamazepine $183 \mathrm{ng} / \mathrm{L}$ and fluoxetine $12 \mathrm{ng} / \mathrm{L}$. Pharmaceuticals also occur in drinking water, with anticonvulsant drug carbamazepine as one of the most frequently detected [12]. A number of studies also report the presence of illicit drugs and their indicators in urban wastewater in Europe, predominantly cocaine, cannabis, amphetamine, 3,4-methylenedioxymethamphetamine (MDMA; ecstasy), but lately also new psychoactive substances (NPSs) [13-15]. Apart from Europe, environmental concerns related to presence of illicit drugs and their metabolites have also been raised in USA, South America and China [16-19] with their levels typically in the range $\mathrm{ng} / \mathrm{L}$. Contamination of water bodies by pesticides, including insecticides with neuroactive action, has been well documented (reviewed by [6]). These compounds have been traditionally recognized as ubiquitous aquatic contaminants with their concentrations reaching levels of $\mu \mathrm{g} / \mathrm{L}$.

\section{Do NCs present an emerging risk to aquatic ecosystems?}

Among the contaminants in the aquatic environment, NCs are probably the ones with the most thoroughly investigated and well-known primary MoA in target species (human, arthropods). Typically, NCs interfere with specific molecular targets such as neurotransmitter receptors, ion channels, enzymes and transporters responsible for the removal of neurotransmitters from the synaptic cleft, and other elements involved in synaptic transmission and propagation of nerve impulses. Although designed to act selectively on target species, their unintended adverse effects are likely in non-target organisms, due to the universal nature of transmission of nerve impulses in animal kingdom. These effects depend on the environmental concentrations, routes of uptake, efficacy of metabolic, detoxification and excretory system, bioaccumulation potential, and also on the level of evolutionary and functional conservation of specific molecular targets of NCs, which is typically very high across phyla $[1,20]$. It is therefore clear that NCs present a hazard to aquatic biota, but whether they really present an emerging risk to aquatic ecosystems is unclear, partly due to the limitations of prospective risk assessment (RA) of chemicals. In prospective RA of chemicals in European Union, neurotoxicity is still assessed only using in vivo test systems with standard oral toxicity studies in rodents and, in case of prospective environmental risk assessment (ERA) of pesticides, in vivo tests with additional mammals and birds as part of evaluation of ecotoxicological effects on terrestrial vertebrates. Delayed neurotoxicity testing, however, is currently required for human health RA only, leaving the potential ecological impacts of untested chemicals and their combined effects to other vertebrates unknown, although compounds that have not been designed as NCs (such as industrial chemicals) could also have unintended neurotoxic properties [21]. Neurotoxic effects of chemicals on aquatic species are not assessed at all. Since neuroactive insecticides are in general classified as toxic to very toxic to aquatic animals, the tiered ERA approach and application of conservative assessment factors basically make the outcomes of standard acute and chronic aquatic ERA [22] sufficiently protective, even though neurotoxicity is not specifically addressed. However, in RA frameworks for pharmaceuticals [23-25], effect assessment of human and veterinary drugs for aquatic animals (required only if predicted environmental concentrations- $\mathrm{PEC}_{\text {surface }}$ water-surpass the action limit of $0.01 \mu \mathrm{g} / \mathrm{L}$ ) is restricted to two standard tests (with invertebrates and fish) and apical endpoints (mortality and only in case of daphnids-reproduction). The only mandatory test with fish is an early life stage test (FELS, according to OECD guideline 210 [26]) with hatching and survival as the principal endpoints. Although the protocol recommends recording of any abnormalities in appearance and behavior (such as uncoordinated swimming, hyperventilation or atypical feeding), such changes have rarely been quantified so the effective values have hardly ever been expressed for behavioral endpoints. Interestingly, even in the new 
draft Guideline [25], additional tailored assessment for pharmaceutical substances with specific MoA has been proposed for antibiotics and endocrine active substances only [25]. Neurotoxicity has been briefly mentioned as potential specific MoA in aquatic environment while behavior has been rightfully recognized as an ecotoxicologically relevant endpoint for NCs. However, no further action regarding tailored assessment of NCs has yet been proposed due to the lack of reliable standardized endpoint and guidelines. Bearing in mind the lengthy test guideline standardization procedures as well as the pressure to limit vertebrate testing, the tailored assessment of neurotoxic effects in aquatic environment with relevant behavioral endpoints is not likely to be expected in near future.

Since the acute toxicity of pharmaceuticals to aquatic biota is generally low, while the existing standard aquatic testing methods are not suitable for addressing neurotoxicity, we can conclude that current prospective RA of chemicals in EU, particularly RA of pharmaceutical compounds, does not adequately address the potential risk of $\mathrm{NCs}$ in aquatic environment and does not provide reliable experimentally derived data for retrospective risk and impact assessment of NCs in the context of Water Framework Directive (WFD).

\section{Experimentally derived evidence of adverse effects of NCs in aquatic organisms}

The evidence of sublethal effects of neuroactive pharmaceuticals reported in scientific literature for aquatic invertebrates, fish and/or amphibians almost exclusively derive from laboratory studies with individual compounds. The adverse effects include changes in brain chemistry, changes in feeding and social behavior, induction of stress and anxiety, changes in locomotion, negative effects on reproduction and development, reduction in the immune system's responsiveness and impact on the efficiency of cryptic behaviors [reviewed by 11 and 20; 27, 28].

Laboratory studies revealed that zebrafish larvae are sensitive to $\mathrm{d}$-amphetamine and cocaine, with similar locomotor response as seen in mammals [29]. Moreover, zebrafish are responsive to the rewarding properties of drugs of abuse [30], exhibit anxiety-like state in cocaine withdrawal [31], robust behavioral responses and physiological changes in MDMA treatment [32], while cannabinoid exposure exhibit persistent developmental impacts [33]. Aside from mortality, exposure to neonicotinoids causes a number of sublethal effects on aquatic organisms, such as feeding inhibition, impaired movement, reduced fecundity, reduced body size and immune-suppression (reviewed by [34]). Sublethal doses of organophosphate insecticides can cause physiological impairment of vital functions in fish, such as feeding, predator avoidance and reproduction [35], as well as neurotoxic effects in fish that correlates with a slow escape response to predator attack [36]. Such adverse neurological outcomes can reduce an organism's ability to survive, grow or reproduce and thus increase the likelihood of population-level disturbances [37].

Although conducted under unrealistic, typical laboratory conditions, in simplified experimental settings and long exposure duration, some of the cited studies have applied environmentally relevant exposure concentrations of individual NCs (Table 1). The results indicate that the adverse, in most cases behavioral effects of

Table 1 Neuroactive compounds (NCs), model organisms, tested concentrations and lowest concentrations with the observed effect(s) in examples of laboratory studies providing experimentally derived evidence of adverse effects of NCs in aquatic organisms

\begin{tabular}{|c|c|c|c|c|}
\hline Neuroactive compound & Model organism & $\begin{array}{l}\text { Tested concentrations } \\
(\mu \mathrm{g} / \mathrm{L})\end{array}$ & $\begin{array}{l}\text { Lowest concentration with the } \\
\text { observed effect(s) }(\mu \mathrm{g} / \mathrm{L})\end{array}$ & References \\
\hline Carbamazepine & Danio rerio & 1,2 and 5 & 1 & {$[27]$} \\
\hline Oxazepam & Lota lota & 1 and 100 & 1 & {$[28]$} \\
\hline D-Amphetamine & Danio rerio & $13,5-2704$ & 13,5 & {$[29]$} \\
\hline Cocaine & Danio rerio & $68-17,000$ & 2000 & \\
\hline Cocaine & Danio rerio & $1000-20,000$ & 5000 & {$[30]$} \\
\hline Cocaine & Danio rerio & $5-51,000$ & $510^{\mathrm{a}}$ & [31] \\
\hline $\begin{array}{l}\text { 3,4-Methylenedioxymethamphetamine } \\
\text { (MDMA, "Ecstasy") }\end{array}$ & Danio rerio & $250-120,000$ & 40,000 & {$[32]$} \\
\hline$\triangle 9$-Tetrahydrocannabinol (THC) & Danio rerio & $300-5000$ & $\begin{array}{l}600 \\
\left(L C_{50}=3650\right)\end{array}$ & [33] \\
\hline Cannabidiol (CBD) & Danio rerio & $70-1250$ & $\begin{array}{l}70 \\
\left(L_{50}=530\right)\end{array}$ & \\
\hline Ethoprophos & Astyanax aeneus & 14 & 14 & {$[36]$} \\
\hline
\end{tabular}

${ }^{a}$ Concentration with the most consistent efficacy; LC50-median lethal concentration 
very low concentrations of NCs that eventually lead to population-level outcomes, can be expected in aquatic ecosystems constantly exposed to complex mixtures of contaminants under stochastic environmental and multistress conditions.

\section{Can we assess, identify and confirm the adverse effects and ecological impacts of NCs in aquatic ecosystems?}

It takes a complex, weight of evidence (WoE) approach based on four complementing lines of evidence (LoE) to assess the ecological impact of overall chemical pressure, and to identify the drivers of mixture risks [38]. Four lines of evidence include: LoE 1: CBM-component-based methods that allow a predictive mixture risk modeling; LoE 2: EBM-effect-based methods (battery of MoA-specific bioanalytical tools); LoE 3: in situ tests and analysis (caged or free-living animals) based on a battery of sufficiently selective and MoA-specific biomarkers of effect measurable on various level of biological organization (from gene expression and enzyme activity to behavior) and LoE 4: biomonitoring (field-derived) data on aquatic communities structure and composition, as an ultimate measure of ecosystem integrity.

Provided that the adequate MoA-specific tools are available, theoretically, the concept could be used to assess the ecological impact of NCs. However, there are currently (too) many limitations and challenges to be addressed. Apart from insecticides, for the vast majority of other NCs (pharmaceuticals and illicit drugs, their metabolites and transformation products), chronic or sublethal effect data for aquatic biota are not available, so in CBM (LoE 1) the chronic data must be either extrapolated from acute endpoints or read across [38, 39] which makes the prediction of chronic toxic pressure from chemicals from this group as well as the assessment of the contribution of NCs to the overall toxic pressure in aquatic ecosystems rather unreliable. With regard to EBM (LoE 2), it is believed that a comprehensive bioanalytical test battery provides integrated information of the effects of the biologically active substances in a water sample [40]. For certain groups of xenobiotics, such as endocrine disruptors (EDs, particularly estrogenic and androgenic compounds) and dioxin-like compounds (DLCs), universal expression of bioassay data, based on the assay's reference compound, biological toxic equivalents (estradiol equivalent (EEQ) or TCDD equivalent (TCDDEQ)) [41, 42] enables quantification of effects. However, in case of NCs diversity of chemical structures, MoAs and specific molecular targets, and consequently the lack of one prototype compound that could be used as a reference, makes such universal bioanalytical approach difficult to develop. Therefore, inhibition of AChE (expressed as parathion EQ) is still the only commonly used in vitro endpoint for specific neurotoxicity [43], limiting the assessment of neurotoxic effects to insecticides and a handful of other NCs with similar MoA, while ignoring all the other MoAs and potential adverse effects. Similarly, the most well-known and basically the only commonly used biomarker (LoE 3) of effect for neurotoxicity is the acetylcholinesterase (AChE) inhibition, typically measured in the brain or whole animal homogenate from free-living or caged animals [21]. While some already available additional in vitro bioanalytical tools, such as neuronal and glial cell viability assays, precursor cell differentiation and apoptosis assays using neuroblastoma cells, myelination, neurotransmitter receptor profiles in neuroblastoma cells and interference with neurotransmitter enzymes or postsynaptic receptors are expected to be validated for water quality assessment soon [43], there is little progress in expanding the "core battery of biomarkers" (according to [44]) to comprehensively address the neurotoxicity in aquatic ecosystems. One way forward might be to use online (multispecies) biomonitoring devices instead of simple caging and to observe, in real-time, behavioral changes of exposed animals. However, this approach limits the assessment to few places of interest (hot spots) and could not be applied to monitor natural populations in aquatic ecosystems. Laboratory studies with aquatic animals exposed to environmentally realistic sublethal concentrations of NCs imply that the behavioral changes are pivot key events leading to adverse outcomes of NCs. But prior to behavioral alterations, significant changes in brain neurochemistry must occur [21]. Monitoring such changes using properly identified and carefully selected neurochemical biomarkers seems to be a promising strategy for impact assessment of NCs in aquatic ecosystems. So far, limited progress has been made in establishment of specific biomarker response patterns for NCs that could be widely accepted and used in ecological impact assessment.

\section{Impact assessment of NCs in aquatic ecosystems and relevance of Adverse Outcome Pathway (AOP) framework}

The effects of toxicants, including NCs, can be first observed already at the molecular level, and are followed by subsequent (measurable) responses on different levels of biological organization that culminate in adverse effects at the level of individual or population. Any of alterations in molecular, cellular, biochemical and physiological processes are potential biomarkers which, ideally, can provide valuable early warning signals of environmental contamination by specific group of compounds. However, their biological significance in terms of linkage of specific early responses to population and ecosystem 
consequences has been stressed as the key issue limiting the use of biomarker approach in ERA [45]. Therefore, it is important to have a linkage framework on the subindividual level by which the response can be connected to potential adverse outcomes, and which would highlight the usefulness of biomarkers in mapping the risk of chemical exposure on all the biological levels at which a chemical is likely to act [46].

A concept that could provide a solid framework to link molecular or cellular events to a whole organism is the Adverse Outcome Pathway (AOP) [42]. AOPs represent biologically plausible and empirically supported links between a series of Key Events (KE), which are measurable changes at the molecular, cellular, tissue, organ, individual, and population level, from a Molecular Initiating Event (MIE, the initial point of chemical interaction) to an Adverse Outcome (AO) [47]. All AOPs developed so far (or being still under development) are available in an open-source platform AOP-Wiki (https://aopwiki.org). Here, specific AOPs with MIEs and/or KE related to impairment of molecular targets associated to neuronal functions can be searched and extracted. By description, AOPs are chemical agnostic. However, matching events described within AOPs with responsive biomarkers observed for NCs can contribute to the strengthening of the weight of evidence for a causal relationship between chemical exposure and adverse health outcomes [47]. Such approach could help in identification of biomarkers that could really serve as early warning indicators that respond before measurable effects on individual performance and population/community dynamics occur [48].

Proof of concept where several biomarkers of effects were linked to adverse reproductive outcomes using information collected in specific AOPs has been successfully demonstrated for phthalate exposure in human studies [47]. Integration of biological responses to chemicals into the AOP framework was also presented by Lee et al. [46], while Oki and Edwards [49] provided a proof of concept of integrating multiple complementary toxicity datasets explored and determined by computational data mining approach in the development of AOPs.

\section{Biomarkers of effect of NCs and AOPs}

Synaptic transmission, the main target of the majority of NCs, is a complex, well coordinated, multi-stage process starting with biosynthesis of neurotransmitters, their exocytosis, binding to specific postsynaptic receptors and induction of the resulting postsynaptic potential, and finally removal of neurotransmitters from the synaptic cleft (either by enzymatic degradation or by specific transport proteins). Each of these steps is a possible target of NCs and, if measurable and sensitive enough, a potential biomarker of effect of NCs. The strengths and limitations of these, so-called neurochemical biomarkers in the field of ecotoxicology have been reviewed by Basu [37], but the question of translation of measured changes to structural or functional damage to the nervous system and ultimately to adverse outcomes remained open, as well as their integration into ecological risk and impact assessment frameworks and practices.

For the purpose of this discussion paper, and guided by AOPs including MIEs and/or KE related to impairment of neuronal functions, we searched for the data from (eco)toxicological studies measuring parameters with relevance in definition of biomarkers of effect of NCs in aquatic organisms. The search was performed in Scopus, (https://www.scopus.com/search/), ScienceDirect (https://www.sciencedirect.com/) and PubMed (https:// pubmed.ncbi.nlm.nih.gov/) databases using combinations of the following keywords: aquatic environment, biomarkers, effects, fish, invertebrates, pharmaceuticals, non-target organisms, neuroactive substances, neurochemical biomarkers, neurotransmitters, pesticides, psychoactive substances, stimulants. For the advanced search, basic key words were also combined with the additional ones, mostly referring to the specific biomarkers defined in Table 2. From the search results, we have selected (eco)toxicological studies focusing on effects on NCs and their mixtures on specific neurochemical biomarkers in aquatic invertebrates and fish. Based on those selected studies and MIEs and KEs defined in the available AOPs at AOP-Wiki, we extracted 20 endpoints with relevance in definition of biomarkers of effect of NCs and potential candidates for development of corresponding impact assessment tools (Table 2). This list, however, can easily be extended due to the diversity and complexity of elements of neurotransmitter signaling pathways.

It transpired that among almost 400 AOPs registered at AOP-Wiki platform, there are 37 potentially relevant as sources of candidates for biomarkers of effect of NCs (Table 2). The AOP examples presented in this review are available in the AOP knowledgebase (https://aopwi ki.org), and their overview together with relevant MIEs/ KEs, AOs, taxonomic applicability, present status and web addresses for each AOP, are provided in Supplementary material (Additional file 1: Table S1). Among them, there are only 4 with confirmed OEDC status and open for citation and comments (AOP10, AOP 12, AOP13, and AOP48), while the others are still at different stages of development. All these AOPs include 17 different MIEs and/or KEs, related to different stages of synaptic transmission or propagation of nerve impulses. From the selected (eco)toxicity studies with different aquatic species as model organisms exposed to NCs, 10 different endpoints are extracted as potentially relevant biomarkers of effect of NCs. When comparing molecular targets 
Table 2 Overview of molecular responses with relevance in definition of biomarker of effects of NCs measured in aquatic organisms in (eco)toxicological studies and AOPs including corresponding MIE or KE

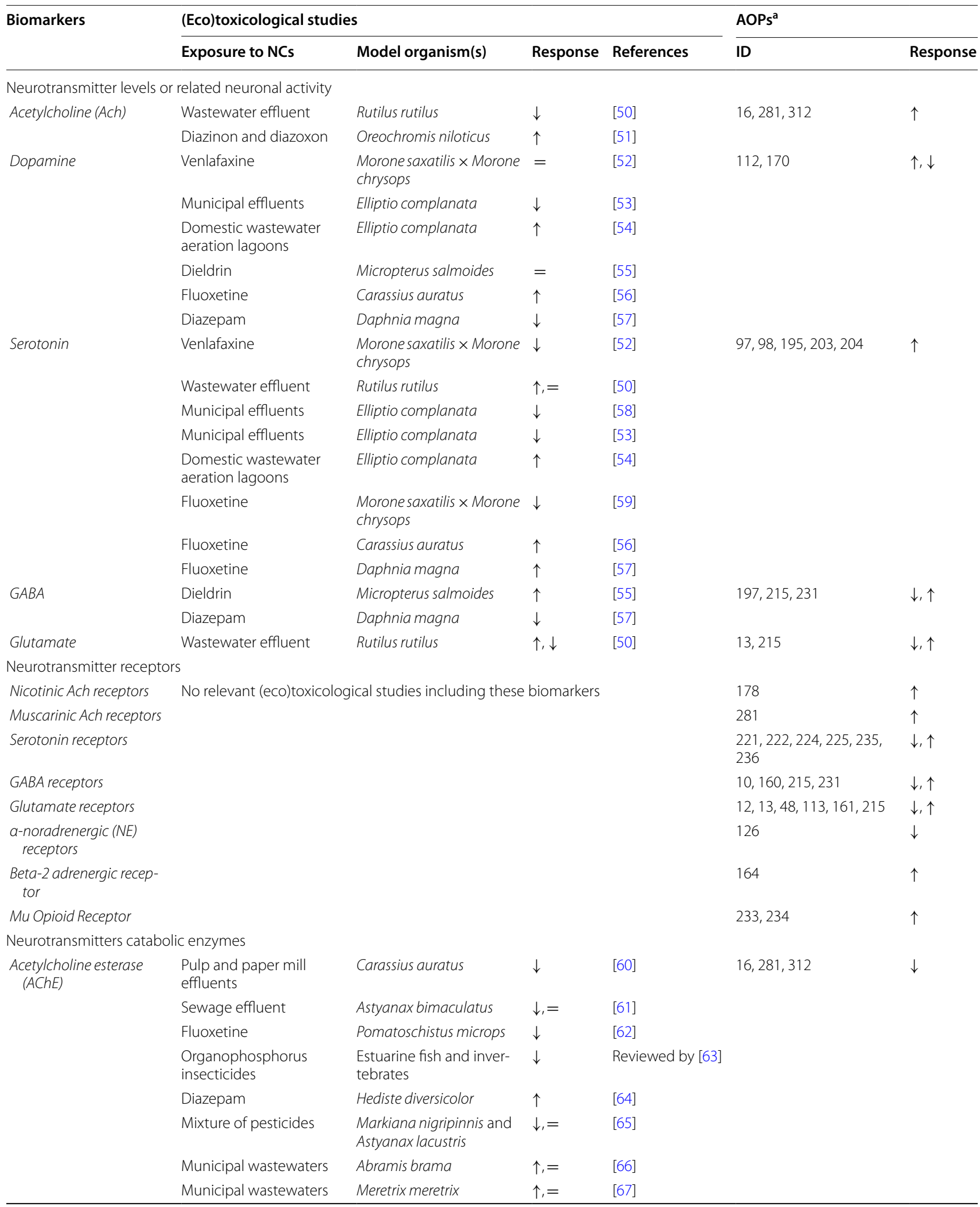


Table 2 (continued)

\begin{tabular}{|c|c|c|c|c|c|c|}
\hline \multirow[t]{2}{*}{ Biomarkers } & \multicolumn{4}{|l|}{ (Eco)toxicological studies } & \multicolumn{2}{|c|}{$\mathrm{AOPs}^{\mathrm{a}}$} \\
\hline & Exposure to NCs & Model organism(s) & Response & References & ID & Response \\
\hline \multirow[t]{6}{*}{ Monoaminoxidase (MAO) } & Caffeine, carbamazepine & Corbicula fluminea & $=$ & [68] & \multirow{7}{*}{\multicolumn{2}{|c|}{$\begin{array}{l}\text { No AOPs including these biomark- } \\
\text { ers as MIE/KE }\end{array}$}} \\
\hline & $\begin{array}{l}\text { Wastewater treatment } \\
\text { plant effluents }\end{array}$ & Different fish species & $\uparrow, \downarrow$ & {$[69]$} & & \\
\hline & $\begin{array}{l}\text { Pulp and paper mill } \\
\text { effluents }\end{array}$ & Carassius auratus & $\downarrow$ & {$[60]$} & & \\
\hline & Municipal effluents & Elliptio complanata & $\uparrow$ & {$[58]$} & & \\
\hline & $\begin{array}{l}\text { Domestic wastewater } \\
\text { aeration lagoons }\end{array}$ & Elliptio complanata & $\uparrow$ & [54] & & \\
\hline & $\begin{array}{l}\text { Carbamazepine, fluox- } \\
\text { etine }\end{array}$ & Hediste diversicolor & $\downarrow$ & [70] & & \\
\hline $\begin{array}{l}\text { GABA transaminase } \\
\text { (GABA-T) }\end{array}$ & $\begin{array}{l}\text { Pulp and paper mill } \\
\text { effluents }\end{array}$ & Carassius auratus & $\uparrow, \downarrow$ & {$[60]$} & & \\
\hline \multicolumn{7}{|l|}{ Neurotransmitter transporters } \\
\hline \multirow[t]{3}{*}{ Dopamine transporters } & Municipal effluents & Elliptio complanata & $\uparrow$ & {$[53]$} & \multirow{3}{*}{\multicolumn{2}{|c|}{$\begin{array}{l}\text { No AOPs including these biomark- } \\
\text { ers as MIE/KE }\end{array}$}} \\
\hline & $\begin{array}{l}\text { Domestic wastewater } \\
\text { aeration lagoons }\end{array}$ & Elliptio complanata & $\uparrow$ & {$[54]$} & & \\
\hline & Fluoxetine & Carassius auratus & $\downarrow$ & {$[56]$} & & \\
\hline \multirow[t]{2}{*}{ Serotonin transporters } & Municipal effluents & Elliptio complanata & $\downarrow$ & {$[53]$} & \multirow{2}{*}{\multicolumn{2}{|c|}{$\begin{array}{l}97,98,195,203,204,221, \quad \downarrow, \uparrow \\
222,223,224,225,226\end{array}$}} \\
\hline & $\begin{array}{l}\text { Domestic wastewater } \\
\text { aeration lagoons }\end{array}$ & Elliptio complanata & $\downarrow$ & [54] & & \\
\hline \multicolumn{7}{|c|}{ Voltage-gated ion channels activity } \\
\hline Sodium channels & \multirow{2}{*}{\multicolumn{4}{|c|}{ No relevant (eco)toxicological studies including these biomarkers }} & 94,9 & $\downarrow, \uparrow$ \\
\hline Potassium channels & & & & & 95 & $\downarrow$ \\
\hline
\end{tabular}

MIE Molecular Initiating Event, KE Key Event

${ }^{a}$ The web addresses and status for each AOP are provided in Additional file 1: Table S1

defined by available AOPs and selected (eco)toxicity studies, there are only 7 that are covered by both approaches, while the rest (13) are covered only by one approach.

\section{Neurotransmitter (NT) levels or related neuronal activity}

Although playing a central role in relaying information at chemical synapses in the CNS, minor changes in the concentration of neurotransmitters can lead to neurodegenerative diseases [71]. Based on AOP database and corresponding references, changes in neurotransmitter (NT) levels or the associated neuronal activity can lead to increased mortality, increased predation and population decline, decreased reproductive success, impairment of learning and memory, depending on NT [72-74]. On the contrary, population increase has been also suggested as an $\mathrm{AO}$ in one AOP including increased serotonin level as KE [72]. Most of the AOPs refer to increase in NT levels as KEs leading to adverse outcome, especially in the case of acetylcholine and serotonin levels. In addition to AOP data, results of (eco)toxicological studies also imply to NT levels as sensitive biomarkers of NCs. It was shown that effects of NCs on NT levels strongly depend on the type of exposure, model/bioindicator species, brain region used for the analyses and gender, so both increase and decrease can be detected in levels of each NT [5059]. This means that, in real-life exposures, being influenced by many factors, the response of an organism to various NCs on the level of NTs release and their resulting levels is rather unpredictable, so increased, decreased or unchanged NT levels can be measured in exposed in comparison to basal levels in unexposed organisms. On the other hand, AOPs mostly refer to increase in NT levels as KEs. Such consistent nature of KEs reported in AOPs does not fully correspond to real-life scenario, which makes integration of biomarker data into available AOPs and prediction of AOs difficult to perform. Hence, development of additional AOPs including decrease in NT levels for each NT would be of great importance for reliable and accurate prediction of AOs.

\section{Neurotransmitter receptors}

In the synapse, released neurotransmitters can bind to and activate specific receptors on adjacent, postsynaptic neurons [37]. Action on neurotransmitter receptors 
is primary MoA of many NCs. Some of the examples are neonicotinoid insecticides binding to the nicotinic acetylcholine receptors (reviewed by [21]) and antipsychotics acting as antagonists of dopamine and serotonin receptors. Activation and inhibition of NT receptors is included as KE in $21 \mathrm{AOPs}$, indicating a significant role of this step of neurotransmission in neural functions. Most of the AOPs are related to changes in the activity of serotonin, GABA and glutamate receptors, with both inactivation and activation of receptors as type of the event. The suggested AOs are increased/decreased depression and increased agitation for serotonin receptors, epileptic seizures for GABA receptors (AOP10; $[75,76]$ ) and impairment of learning and memory for glutamate receptors (AOP12; AOP13; AOP48; [74, 77, 78]). There are also available AOPs related to activation of cholinergic receptors [79], while dopamine receptors are completely neglected in AOP framework. Although included in several AOPs as events which impairment leads to various AOs, to our knowledge there are no relevant (eco)toxicity studies dealing with effects of NCs on the activity of NT receptors. Based on their relevance in primary MoA of NCs, and considering the information derived from AOPs, they seem to be promising candidates for sensitive biomarkers of effect of NCs, so intensive research directed to synchronization of (eco)toxicological research in non-target organisms and present AOPs is highly recommended.

\section{Neurotransmitters catabolic enzymes and transporters}

An essential step in synaptic transmission is the removal of NT from the synaptic cleft, which happens by diffusion, enzymatic degradation or reuptake by specific transporters. AChE is a target of many NCs (such as organophosphorous and carbamate insecticides) with primary MoA related to inhibition of these enzymes, while NT transporters are common targets of neuroactive pharmaceuticals (such as antidepressants acting as inhibitors of serotonin reuptake by transporter (5-HTT)). According to available AOPs, AChE inhibition leads to increased mortality and neurodegeneration [73]. It is also one of the most studied neurochemical biomarkers in (eco)toxicological research where both inhibition and stimulation of enzyme activity was detected in different organisms [60-67]. Monoamine oxidase (MAO), catabolic enzyme degrading dopamine and serotonin [37], was also well studied in (eco)toxicological research with changes in the activity noticed in different organisms exposed to NCs and their mixtures [54, 58, 60, 68-70]. However, available AOPs do not include this potential biomarker as MIE or KE. Among the NT transporters, dopamine and serotonin transporters are promising biomarkers based on the (eco)toxicological studies
[53, 54, 56], but AOPs include only serotonin transporters as MIEs or KEs. Inhibition or decrease of the serotonin transporter activity (5-HTT) is included in 11 different AOPs, suggesting increased predation, changes in reproductive success and population size [72], as well as increased depression and agitation as most prominent AOs. Overall, the use of information on the responses related to either NT receptors or NT removal are not well synchronized in (eco)toxicological research and AOPs, implying the necessity of integration of promising biomarkers such as MAO, GABA transaminase (GABA$\mathrm{T})$ and dopamine transporters into AOP framework.

\section{Voltage-gated ion channels activity}

Although being of crucial importance in propagation of nerve impulses, the activity of sodium and potassium voltage-gated channels is completely neglected in (eco) toxicological studies, but it is included in 6 different AOPs suggesting reduced survival [72], seizures and epilepsy as the most prominent AOs. Incorporating these parameters in (eco)toxicological studies would provide more information on their applicability as biomarkers.

\section{Future perspectives and strategies in definition of specific biomarker response patterns for NCs}

Even though we live in the age of information and informatics and intensified efforts invested worldwide in creation and curation of open, user-friendly databases and software, with enormous quantities of information available with a click of a mouse, it seems that we are still living and working in our own small bubbles, rather selfsufficient and ignorant about the developments outside our narrow field. Unfortunately, environmental research is not exempted. When it comes to neuro(eco)toxicological research, it seems that different research communities co-exist and develop separately, in parallel, without much (critically needed) synchronization and harmonization.

A typical example to illustrate these rather hard (self) accusations is the fact that despite the continuously emerging findings on MoA of NCs and other emerging contaminants from the mechanistic laboratory studies, it seems that the "core biomarkers" (as presented already 15 years ago by Pampanin et al. [44]) including inhibition of acetylcholinesterase (AChE) activity, metallothionein (MT) concentration, induction of cytochrome P450 1A enzymes (CYP1A), and the activity of antioxidant and detoxification enzymes are still the first choice in field ecotoxicological studies, regardless the sources of pollution and type of compounds inducing (or not) the measured parameters. In many studies, including those related to exposure to NCs, such traditional approach most often results in inconsistent and low- or no-effect responses. With a broad spectrum of more specific and sensitive 
biomarkers of effect of NCs presented in this paper, this concept should be revised, to establish a strategy which will be based on measurement of parameters directly related to disturbance of neurotransmission and propagation of nerve impulses, in cases of suspected NCs pollution and their ecological impact assessment.

On the other hand, "hard (eco)toxicological science" seems to be unaware of the high value of basic physiological research findings for risk-oriented environmental research and management. Approach to study the concentration-dependent response of organism can help to understand mechanism of toxicity [11], but laboratory experiments are too often conducted using environmentally unrealistic exposure concentrations of NCs which makes the ecological relevance of such findings rather limited. Valuable behavioral laboratory studies with $\mathrm{NCs}$ are being vastly underused because sub-individual parameters are rarely simultaneously measured and the opportunity to feed the results into existing or newly suggested AOPs and contribute to identification of specific biomarker response patterns for NCs is in most cases lost. Although the AOP concept has been proposed and widely promoted for years, it seems that the research community gathered around the concept is rather hermetic and strictly divided between human and ecological applications. The AOP concept starts resembling the classical literature in terms that everybody has heard about it (and readily uses the buzz word in the scientific publications) but not many (eco)toxicologists have really embraced it. Traditional (eco)toxicologists seem to be rather reluctant to either plan the experimental work so that the results might feed into AOPs under development, or to extract valuable information and, more importantly, knowledge gaps from existing AOPs when planning future research.

Bearing in mind that the neurochemical biomarkers present only one tiny piece of a big neuro(eco)toxicological puzzle comprehensively presented in excellent review by Legradi et al. [21], "out of the box" way of thinking requires revisiting the role of biomarkers and making the most of their full potential in ecotoxicological research and ecological impact assessment. To do so, there are at least three currently parallel research avenues that should be taken synergistically in development of biomarkerbased strategy for impact assessment of NCs in aquatic environment and prediction of their adverse effects (Fig. 1).

I. Mechanistic laboratory studies using cell-culture based assays and laboratory organisms (standard and non-standard aquatic invertebrates, fish), analyzing wide spectra of NCs with different primary MoA and substantial number of their possible molecular, biochemical and/or behavioral targets. Such investigations provide data on mechanism of toxic effects of NCs, regardless of their primary MoA, in different experimental models. They enable establishment of the database on possible and most responsive biomarkers of effect of NCs.

II. Field studies using caged or wild, sentinel species from the aquatic environment (contaminated by NCs and pristine sites) for the analyses of the selected biomarkers of effect of NCs. Such investigations, supported by chemical analysis, chemoinformatic approach, component-based predictive modeling and effect-based (bioanalytical) tools aimed to identification and quantification of NCs and their potential risk to aquatic ecosystems, would provide information on cause-effect relationships between detected contaminants and responses measured in situ, enable validation of experimentally derived battery of specific biomarkers, and establishment of biomarker response patterns for identification of compounds with neuroactive properties in environmental mixtures and their ecological impact.

III. Integration in the existing AOPs and development of new AOPs which include biomarkers of effect of NCs defined in I and II as MIEs and/or KEs, with implications for AO.

The synchronization of biomarker research via these three research avenues is of crucial importance for gaining comprehensive results and selection of the most sensitive and most specific parameters. The search for such biomarkers does not end with the parameters presented in this paper, but can be extended to other events such as control of neurotransmitter release, as well as functional or structural changes in nerve cells.

\section{Conclusion}

Current approaches to assess the impacts of NCs on the exposed aquatic ecosystems are still poorly established although the development and implementation of appropriately targeted water management strategies critically depend on realistic estimations and relevant data. Under-, but also over-estimation of impacts related to NCs in the environment could critically jeopardize effectiveness of abatement measures. In order to realistically identify and assess the role of NCs pollution on the ecological integrity of aquatic ecosystems, we advocate the development and application of AOP embedded biomarker-based strategy.

Lack of well-characterized and widely accepted biomarkers clearly related to adverse effects in the exposed organisms, and incomplete AOPs incorporating these 


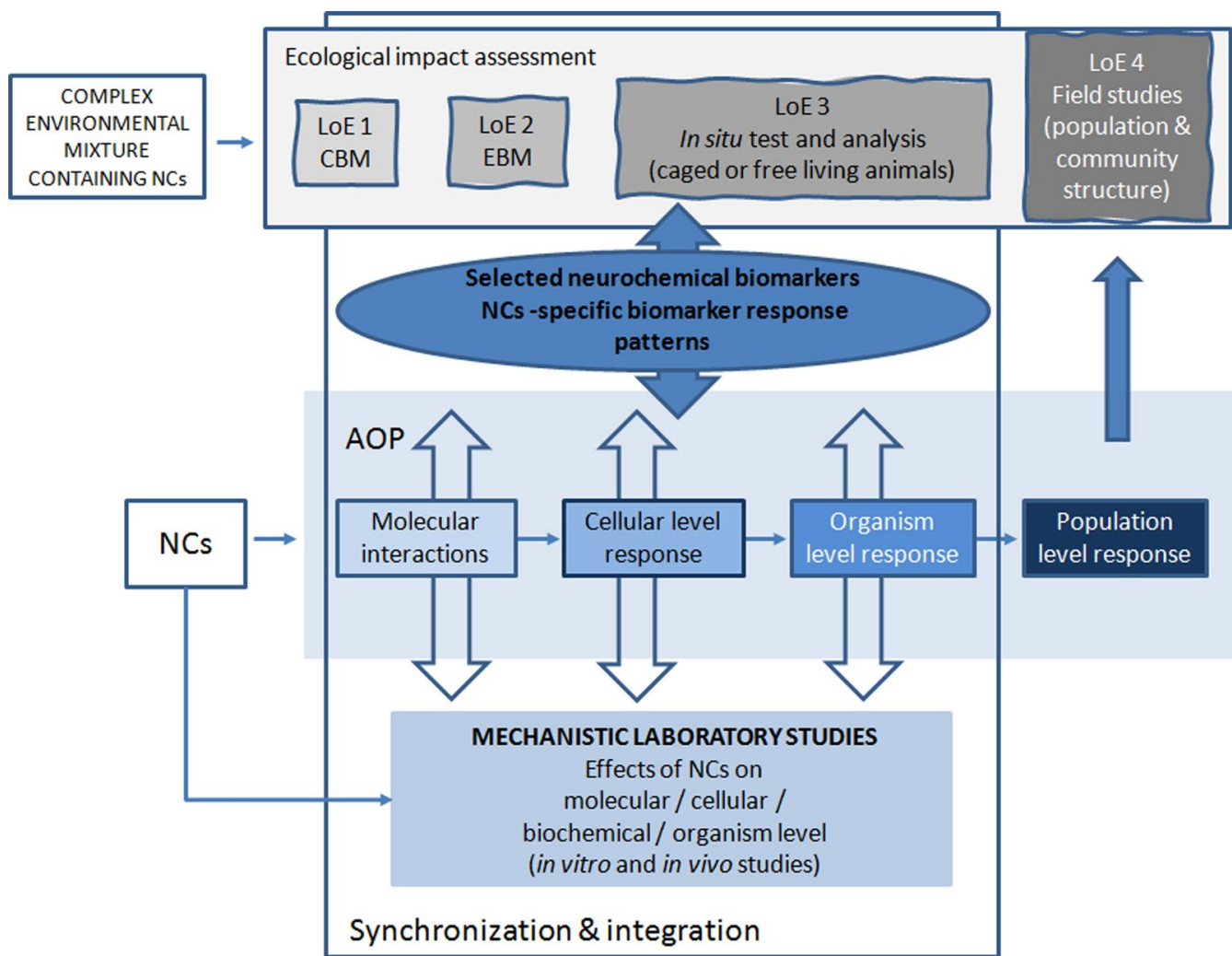

Fig. 1 Selection of specific biomarkers, identification, confirmation and validation of biomarker's response patterns for impact assessment of neuroactive compounds in the aquatic environment: synchronization of mechanistic and field studies and integration into AOP framework. NCS neuroactive compounds, LOE line of evidence, CBM component-based predictive mixture modeling, EBM effect-based methods (bioanalytical tools)

biomarkers as MIEs/KEs, still represent challenges in investigations aimed at development of biomarkerbased strategy for impact assessment of NCs in the aquatic environment. The holistic approach in biomarker research that integrates data resulting from synchronized mechanistic laboratory studies (in vitro and in vivo) and field studies is essential for determination of sensitive biomarkers of effect of NCs and related response patterns. Special emphasis should be put on further development and utiliation of adverse AOP framework database in establishment of a strategy for impact assessment of $\mathrm{NCs}$ in the aquatic environment.

\footnotetext{
Abbreviations

AO: Adverse outcome; AOP: Adverse outcome pathway; Ach: Acetylcholine; AChE: Acetylcholinesterase; CBM: Component-based predictive mixture modeling; ERA: Environmental risk assessment; EBM: Effect-based methods; GABA-T: GABA transaminase; GC-HRMS: Gas chromatography coupled to high-resolution mass spectrometry; 5-HTT: Serotonin transporter; KE: Key event; LC-HRMS: Liquid chromatography coupled to high-resolution mass spectrometry; LoE: Line of evidence; MAO: Monoamine oxidase; MIE: Molecular initiating event; MoA: Mode of action; NCs: Neuroactive compounds; NT: Neurotransmitter; NTS: Non-target screening; OEDC: Organisation for Economic Co-operation and Development; RA: Risk assessment; WoE: Weight of evidence.
}

\section{Supplementary Information}

The online version contains supplementary material available at https://doi. org/10.1186/s12302-021-00557-0.

Additional file 1: Table S1. Overview of AOPs with relevance in definition of biomarkers of effect of neuroactive compounds (NCs).

\section{Acknowledgements}

The authors acknowledge support of the Ministry of Education, Science and Technological Development of the Republic of Serbia (Grant No. 451-03-9/ 2021-14/200125).

\section{Authors' contributions}

SK has been responsible for the concept of the manuscript, drafted the manuscript and was involved in its finalization. IT has been responsible for further elaborating the manuscript and its finalization. IV, DT and TT assisted in drafting the manuscript and contributed specific aspects. All authors read and approved the final manuscript.

\section{Funding}

This research was supported by the Science Fund of the Republic of Serbia, PROMIS, Grant No. 6061817, BIANCO. The paper content is the responsibility of the University of Novi Sad Faculty of Sciences, and it does not reflect the opinion of the Science Fund of the Republic of Serbia.

\section{Availability of data and materials}

Not applicable. 


\section{Declarations}

Ethics approval and consent to participate

Not applicable.

\section{Consent for publication}

Not applicable.

\section{Competing interests}

The authors declare that they have no competing interests.

Received: 11 July 2021 Accepted: 19 September 2021

Published online: 09 October 2021

\section{References}

1. Arnold KE, Brown AR, Ankley GT, Sumpter JP (2014) Medicating the environment: assessing risks of pharmaceuticals to wildlife and ecosystems. Phil Trans R Soc B 369:20130569

2. Cunha DL, Mendes MP, Marques M (2019) Environmental risk assessment of psychoactive drugs in the aquatic environment. Environ Sci Pollut Res 26:78-90

3. Bruni G, Lakhani P, Kokel D (2014) Discovering novel neuroactive drugs through high-throughput behavior-based chemical screening in the zebrafish. Front Pharmacol 5:153

4. Buerge G, Poiger T, Müller MD, Buser H-R (2003) Caffeine, an anthropogenic marker for wastewater contamination of surface waters. Environ Sci Technol 37:691-700

5. de Sousa ML, dos Santos DYAC, Chow F, Pompeo MLM (2021) Caffeine as a contaminant of periphyton: ecological changes and impacts on primary producers. Ecotoxicology 30:599-609

6. Sharma A, Kumar V, Shahzad B, Tanveer M, Sidhu GPS, Handa N, Kohli SK, Yadav P, Bali AS, Parihar RD, Dar OI, Singh K, Jasrotia S, Bakshi P, Ramakrishnan M, Kumar S, Bhardwaj R, Thukral AK (2019) Worldwide pesticide usage and its impacts on ecosystem. SN Appl Sci 1:1446

7. Brack W, Hollender J, López de Alda M, Müller C, Schulze T, Schymanski E, Slobodnik J, Krauss M (2019) High-resolution mass spectrometry to complement monitoring and track emerging chemicals and pollution trends in European water resources. Environ Sci Euro 31:62

8. Busch W, Schmidt S, Kuhne R, Schulze T, Krauss M, Altenburger R (2016) Micropollutants in European rivers: a mode of action survey to support the development of effect-based tools for water monitoring. Environ Toxicol Chem 35(8):1887-1899

9. Zhou S, Di Paolo C, Wu X, Shao Y, Seiler T-B, Hollert H (2019) Optimization of screening-level risk assessment and priority selection of emerging pollutants - The case of pharmaceuticals in European surface waters. Environ Int 128:1-10

10. Brandao FP, Rodrigues S, Castro BB, Goncaves F, Antunes SC, Nunes B (2013) Short-term effects of neuroactive pharmaceutical drugs on a fish species: Biochemical and behavioural effects. Aquat Toxicol 144-145:218-229

11. Sehonova P, Svobodova Z, Dolezelova P, Vosmerova P, Faggio C (2018) Effects of waterborne antidepressants on non-target animals living in the aquatic environment: A review. Sci Total Environ 631-632:789-794

12. Benotti MJ, Trenholm RA, Vanderford BJ, Holady JC, Stanford BD, Snyder SA (2009) Pharmaceuticals and endocrine disrupting compounds in U.S. drinking water. Environ Sci Technol 43:597-603

13. Bade R, Bijlsma L, Sancho JV, Baz-Lomba JA, Castiglioni S, Castrignanỏ E, Causanilles A, Gracia-Lor E, Kasprzyk-Hordern B, Kinyua J, McCall A-K, van Nuijs ALN, Ort C, Plósz BG, Ramin P, Rousis NI, Ryu Y, Thomas KV, de Voogt P, Zuccato E, Hernández F (2017) Liquid chromatography-tandem mass spectrometry determination of synthetic cathinones and phenethylamines in influent wastewater of eight European cities. Chemosphere 168:1032-1041

14. Ort C, van Nuijs ALN, Berset J-D, Bijlsma L, Castiglioni S, Covaci A, de Voogt P, Emke E, Fatta-Kassinos D, Griffiths P, Hernández F, González Mariño I, Grabic R, Kasprzyk-Hordern B, Mastroianni N, Meierjohann A Nefau T, Östman M, Pico Y, Racamonde I, Reid M, Slobodnik J, Terzic S, Thomaidis N, Thomas KV (2014) Spatial differences and temporal changes in illicit drug use in Europe quantified by wastewater analysis. Addiction 109:1338-1352

15. Bijlsma L, Celma A, Castiglioni S, Salqueiro-González N, Bou-Iserte L, BazLomba JA, Reid MJ, Dias MJ, Lopes A, Matias J, Pastor-Alcañiz L, Radonić J, Turk Sekulic M, Shine T, van Nuijs ALN, Hernandez F, Zuccato E (2020) Monitoring psychoactive substance use at six European festivals through wastewater and pooled urine analysis. Sci Total Environ 725:138376

16. Pal R, Megharaj M, Kirkbride KP, Naidu R (2013) Illicit drugs and the environment-a review. Sci Total Environ 463-464:1079-1092

17. Subedi B, Kannan K (2014) Mass loading and removal of select illicit drugs in two wastewater treatment plants in New York State and estimation of illicit drug usage in communities through wastewater analysis. Environ Sci Technol 48:6661-6670

18. Fabregat-Safont D, Ibáñez M, Bijlsma L, Hernández F, Waichman AV, de Oliveira R, Rico A (2021) Wide-scope screening of pharmaceuticals, illicit drugs and their metabolites in the Amazon River. Water Res 200:117251

19. Yao B, Yan S, Lian L, Liu D, Cui J, Song W (2021) Occurrence, distribution, and potential health risks of psychoactive substances in Chinese surface waters. J Hazard Mater 407:124851

20. McDonald MD (2017) An AOP analysis of selective serotonin reuptake inhibitors (SSRIs) for fish. Comp Biochem Physiol C Toxicol Pharmacol 197:19-31

21. Legradi JB, Di Paolo C, Kraak MHS, Van der Geest HG, Schymanski EL, Williams AJ, Dingemans MML, Massei R, Brack W, Cousin X, Begout ML, Van der Oost R, Carion A, Suarez-Ulloa V, Silvestre F, Escher BI, Engwall M, Nilén G, Keiter SH, Pollet D, Waldmann P, Kienle C, Werner I, Haigis A-C, Knapen D, Vergauwen L, Spehr M, Schulz W, Busch W, Leuthold D, Scholz S, vom Berg CM, Basu N, Murphy CA, Lampert A, Kuckelkorn J, Grummt T, Hollert $H$ (2018) An ecotoxicological view on neurotoxicity assessment. Environ Sci Eur 30:46

22. EFSA PPR Panel (EFSA Panel on Plant Protection Products and their Residues) (2013) Guidance on tiered risk assessment for plant protection products for aquatic organisms in edge-of-field surface waters. EFSA J 11(7):3290

23. EMA (European Medicines Agency) (2004) Guideline on environmental impact assessment for veterinary medicinal products phase II. European Medicines Agency (EMA), Committee for medicinal products for veterinary use (CVMP) VICH-GL38.

24. EMA (European Medicines Agency) Committee for medicinal products for human use (CHMP) 2006. Guideline on the environmental risk assessment of medicinal products for human use. Doc. Ref. EMEA/CHMP/ SWP/4447/00 corr. 2

25. EMA (European Medicines Agency) (2018) Guideline on the environmental risk assessment of medicinal products for human use. Draft. EMEA/ CHMP/SWP/4447/00 Rev. 1

26. OECD (Organisation for European Economic Co-operation) 1992 OECD Guideline for testing on chemicals. Fish, Early-life Stage Toxicity Test. OECD 210.

27. Qiang L, Cheng J, Yi J, Rotchell JM, Zhu X, Zhou J (2016) Environmental concentration of carbamazepine accelerates fish embryonic development and disturbs larvae behavior. Ecotoxicology 25:1426-1437

28. Sundin J, Jutfelt F, Thorlacius M, Fick J, Brodin J (2019) Behavioral alterations induced by the anxiolytic pollutant oxazepam are reversible after depuration in a freshwater fish. Sci Total Environ 665:390-399

29. Irons TD, MacPhail RC, Hunter DL, Padilla S (2010) Acute neuroactive drug exposures alter locomotor activity in larval zebrafish. Neurotoxicol Teratol 32:84-90

30. Darland T, Dowling JE (2001) Behavioral screening for cocaine sensitivity in mutagenized zebrafish. Proc Natl Acad Sci 98(20):11691-11696

31. Lopez-Patino MA, Yu L, Cabral H, Zhdanova IV (2008) Anxiogenic effects of cocaine withdrawal in zebrafish. Physiol Behav 93:160-171

32. Stewart A, RiehI R, Wong K, Green J, Cosgrove J, Vollmer K, Kyzar E, Hart P, Allain A, Cachat J, Gaikwad S, Hook M, Rhymes K, Newmann A, Utterback E, Chang K, Kalueff AV (2011) Behavioral effects of MDMA ("Ecstasy") on adult zebrafish. Behav Pharmacol 22(3):275-280

33. Carty DR, Thorton C, Gledhill JH, Willett KL (2018) Developmental effects of cannabidiol and $\Delta 9$-tetrahydrocannabinol in zebrafish. Toxicol Sci 162(1):137-145

34. Sánchez-Bayo F, Goka K, Hayasaka D (2016) Contamination of aquatic environment with neonicotinoids and its implication for ecosystems. Front Environ Sci 4:71 
35. Little EE, Archeski RD, Flerov BA, Kozlovskaya VI (1990) Behavioral indicators of sublethal toxicity in rainbow trout. Arch Environ Contam Toxicol 19:380-385

36. Sandoval-Herrera N, Mena F, Espinoza M, Romero A (2019) Neurotoxicity of organophosphate pesticides could reduce the ability of fish to escape predation under low doses of exposure. Sci Rep 9:10530

37. Basu N (2015) Applications and implications of neurochemical biomarkers in environmental toxicology. Environ Toxicol Chem 34(1):22-29

38. Backhaus T, Brack W, Van den Brink PJ, Deutschmann B, Hollert H, Posthuma L, Segner H, Seiler T-B, Teodorovic I, Focks A (2019) Assessing the ecological impact of chemical pollution on aquatic ecosystems requires the systematic exploration and evaluation of four lines of evidence. Environ Sci Eur 31:98

39. Posthuma L, van Gils J, Zijp MC, van de Meent D, de Zwart D (2019) Species sensitivity distributions for use in environmental protection, assessment, and management of aquatic ecosystems for 12386 chemicals. Environ Toxicol Chem 38:905-917

40. Altenburger R, Scholze M, Busch W, Escher BI, Jakobs G, Krauss M, Krüger J, Neale PA, Aït-Aïssa S, Almeida AC, Seiler T-B, Brion F, Hilscherová K, Hollert H, Novák J, Schlichting R, Serra H, Shao Y, Tindall AJ, Tolefsen KE, de Aragão UG, Williams TD, Kortenkamp A (2018) Mixture effects in samples of multiple contaminants - an inter-laboratory study with manifold bioassays. Environ Int 114:95-116

41. Behnisch PA, Hosoe K, Sakai S (2001) Combinatorial bio/chemical analysis of dioxin and dioxin-like compounds in waste recycling, feed/food, humans/wildlife and the environment. Environ Int 27:495-519

42. Leusch FDL, Snyder SA (2015) Bioanalytical tools: half a century of application for potable reuse. Environ Sci Water Res Technol 1:606

43. Escher B, Neale P, Leusch F (2021) Bioanalytical Tools in Water Quality Assessment - 2nd Edition. IWA Publishing. elSBN 9781789061987.

44. Pampanin DM, Viarengo A, Garrigues P, Andersen OK (2006) Background for the BEEP Stavanger workshops: Biological effects on marine organisms in two common, large, laboratory experiments and in a field study: Comparison of the value (sensitivity, specificity, etc.) of core and new biomarkers. Aquat Toxicol 78S:S1-4

45. Hagger JA, Jones MB, Leonard DRP, Owen R, Galloway TS (2006) Biomarkers and integrated environmental risk assessment: are there more questions than answers? Integr Environ Assess Manag 2(4):312-329

46. Lee JW, Won E-J, Raisuddin S, Lee J-S (2015) Significance of adverse outcome pathways in biomarker-based environmental risk assessment in aquatic organisms. J Environ Sci 35:115-127

47. Baken KA, Lambrechts N, Remy S, Mustieles V, Rodríguez-Carrillo A, Neophytou CM, Olea N, Schoeters G (2019) A strategy to validate a selection of human effect biomarkers using adverse outcome pathways: Proof of concept for phthalates and reproductive effects. Environ Res 175:235-256

48. Forbes VE, Palmqvist $A$, Bach $L$ (2006) The use and misuse of biomarkers in ecotoxicology. Environ Toxicol Chem 25:272-280

49. Oki NO, Edwards SW (2016) An integrative data mining approach to identifying adverse outcome pathway signatures. Toxicology 350-352:49-61

50. David A, Lange A, Tyler CR, Hill EM (2018) Concentrating mixtures of neuroactive pharmaceuticals and altered neurotransmitter levels in the brain of fish exposed to a wastewater effluent. Sci Total Environ 621:782-790

51. Girón-Pérez MI, Zaitseva G, Casas-Solis J, Santerre A (2008) Effects of diazinon and diazoxon on the lymphoproliferation rate of splenocytes from Nile tilapia (Oreochromis niloticus): The immunosuppressive effect could involve an increase in acetylcholine levels. Fish Shellfish Immunol 25:517-521

52. Bisesi JH Jr, Bridges W, Klaine SJ (2014) Effects of the antidepressant venlafaxine on fish brain serotonin and predation behavior. Aquat Toxicol 151:88-96

53. Gagne F, Blaise C, Hellou J (2004) Endocrine disruption and health effects of caged mussels, Elliptio complanata, placed downstream from a primary-treated municipal effluent plume for 1 year. Comp Biochem Physiol C Toxicol Pharmacol 38(1):33-44

54. Gagne F, Blaise C, Andre C, Gagnon C, Salazar M (2007) Neuroendocrine disruption and health effects in Elliptio complanata mussels exposed to aeration lagoons for wastewater treatment. Chemosphere 68:731-743

55. Martyniuk CJ, Feswick A, Spade DJ, Kroll KJ, Barber DS, Denslow ND (2010) Effects of acute dieldrin exposure on neurotransmitters and global gene transcription in largemouth bass (Micropterus salmoides) hypothalamus. Neurotoxicology 31:356-366

56. Mennigen JA, Martyniuk CJ, Crump K, Xiong H, Zhao E, Popesku J, Anisman H, Cossins AR, Xia X, Trudeau VL (2008) Effects of fluoxetine on the reproductive axis of female goldfish (Carassius auratus). Physiol Genomics 35:273-282

57. Rivetti C, Climent E, Gómez-Canela C, Barata C (2019) Characterization of neurotransmitter profiles in Daphnia magna juveniles exposed to environmental concentrations of antidepressants and anxiolytic and antihypertensive drugs using liquid chromatography-tandem mass spectrometry. Anal Bioanal Chem 411:5867-5876

58. Gagne F, Blaise C (2003) Effects of municipal effluents on serotonin and dopamine levels in the freshwater mussel Elliptio complanata. Comp Biochem Physiol C Toxicol Pharmacol 36(2):117-125

59. Gaworecki KM, Klaine SJ (2008) Behavioral and biochemical responses of hybrid striped bass during and after fluoxetine exposure. Aquat Toxicol 88(4):207-213

60. Basu N, Ta CA, Waye A, Mao J, Hewitt M, Arnason JT, Trudeau VL (2009) Pulp and paper mill effluents contain neuroactive substances that potentially disrupt neuroendocrine control of fish reproduction. Environ Sci Technol 43(5):1635-1641

61. Bisognin RP, Wolff DB, Carissimi E, Prestes OD, Zanella R, Storck TR, Clasen B (2020) Potential environmental toxicity of sewage effluent with pharmaceuticals. Ecotoxicology 29:1315-1326

62. Duarte IA, Pais MP, Reis-Santos P, Cabral HN, Fonseca VF (2019) Biomarker and behavioural responses of an estuarine fish following acute exposure to fluoxetine. Mar Environ Res 147:24-31

63. Fulton MH, Key PB (2001) Acetylcholinesterase inhibition in estuarine fish and invertebrates as an indicator of organophosphorous insecticide exposure and effects. Environ Toxicol Chem 20(1):37-45

64. Nogueira AF, Nunes B (2021) Acute and chronic effects of diazepam on the polychaete Hediste diversicolor: Antioxidant, metabolic, pharmacologic, neurotoxic and behavioural mechanistic traits. Environ Toxicol Pharmacol 82:103538

65. Rossi AS, Fantón N, Michlig MP, Repetti MR, Cazenave J (2020) Fish inhabiting rice fields: Bioaccumulation, oxidative stress and neurotoxic effects after pesticides application. Ecol Indic 113:106186

66. Tenji D, Micic B, Sipos S, Miljanovic B, Teodorovic I, Kaisarevic S (2020) Fish biomarkers from a different perspective: evidence of adaptive strategy of Abramis brama (L.) to chemical stress. Environ Sci Eur 32:47

67. Wan R, Meng F, Fu W, Wang Q, Su E (2015) Biochemical responses in the gills of Meretrix meretrix after exposure to treated municipal effluent. Ecotoxicol Environ Saf 111:78-85

68. Aguirre-Martínez GV, André C, Gagné F, Martín-Díaz LM (2019) The effects of human drugs in Corbicula fluminea. Assessment of neurotoxicity, inflammation, gametogenic activity, and energy status. Ecotoxicol Environ Saf 148:652-663

69. Arini A, Cavallin JE, Berninger JP, Marfil-Vega R, Mills M, Villeneuve DL, Basu N (2016) In vivo and In vitro neurochemical-based assessments of wastewater effluents from the Maumee River area of concern. Environ Pollut 211:9-19

70. Maranho LA, André C, DelValls TA, Gagné F, Martín-Díaz ML (2015) Toxicological evaluation of sediment samples spiked with human pharmaceutical products: Energy status and neuroendocrine effects in marine polychaetes Hediste diversicolor. Ecotoxicol Environ Saf 118:27-36

71. Harris KD, Weiss M, Zahavi A (2014) Why are neurotransmitters neurotoxic? An evolutionary perspective. F1000 Res 3:179

72. Fay KA, Villeneuve DL, LaLone CA, Song Y, Tollefsen KE, Ankley GT (2017) Practical approaches to adverse outcome pathway development and weight-of-evidence evaluation as illustrated by ecotoxicological case studies. Environ Toxicol Chem 36:1429-1449

73. Russom CL, LaLone CA, Villeneuve DL, Ankley GT (2014) Development of an adverse outcome pathway for acetylcholinesterase inhibition leading to acute mortality. Environ Toxicol Chem 33:2157-2169

74. Sachana M, Rolaki A, Bal-Price A (2018) Development of the Adverse Outcome Pathway (AOP): Chronic binding of antagonist to N-methylD-aspartate receptors (NMDARs) during brain development induces impairment of learning and memory abilities of children. Toxicol Appl Pharmacol 354:153-175 
75. Gong P, Hong H, Perkins EJ (2015) Ionotropic GABA receptor antagonisminduced adverse outcome pathways for potential neurotoxicity biomarkers. Biomark Med 9(11):1225-1239

76. Gong P, Perkins E (2019) Adverse Outcome Pathway on binding to the picrotoxin site of ionotropic GABA receptors leading to epileptic seizures in adult brain, OECD Series on Adverse Outcome Pathways, No. 11, OECD Publishing, Paris, https://doi.org/10.1787/9226875e-en.

77. Sachana M, Munn S, Bal-Price A (2016) Adverse Outcome Pathway on binding of agonists to ionotropic glutamate receptors in adult brain leading to excitotoxicity that mediates neuronal cell death, contributing to learning and memory impairment. OECD Series on Adverse Outcome Pathways, No. 6, OECD Publishing, Paris, https://doi.org/10.1787/5jlr8 vqgm630-en.

78. Tschudi-Monnet F, Fitzgerald R (2018) Adverse Outcome Pathway on chronic binding of antagonist to $\mathrm{N}$-methyl-D-aspartate receptors during brain development leading to neurodegeneration with impairment in learning and memory in aging. OECD Series on Adverse Outcome Pathways, No. 8, OECD Publishing, Paris, https://doi.org/10.1787/95f569ad-en.

79. LaLone CA, Villeneuve DL, Wu-Smart J, Milsk RY, Sappington K, Garber KV, Housenger J, Ankley GT (2017) Weight of evidence evaluation of a network of adverse outcome pathways linking activation of the nicotinic acetylcholine receptor in honey bees to colony death. Sci Total Environ 584-585:751-775

\section{Publisher's Note}

Springer Nature remains neutral with regard to jurisdictional claims in published maps and institutional affiliations.

\section{Submit your manuscript to a SpringerOpen ${ }^{\circ}$ journal and benefit from:}

- Convenient online submission

- Rigorous peer review

- Open access: articles freely available online

- High visibility within the field

- Retaining the copyright to your article

Submit your next manuscript at $\boldsymbol{\nabla}$ springeropen.com 